\title{
Modeling of production indicators of timber carting out from the forest territory depending on the natural and climatic conditions
}

\author{
Alexander Mokhirev ${ }^{1}$, Sergey Medvedev ${ }^{1^{*}}$, and Natalia Bragina ${ }^{1}$ \\ ${ }^{1}$ Reshetnev Siberian State University of Science and Technology, 29 Pobedy Street, 662543, \\ Lesosibirsk Russia
}

\begin{abstract}
The article is devoted to the research of the dependence of timber carting out (logging activity) on natural and climatic conditions. Mathematical models are obtained for these dependencies. The modelling was performed for various timber harvesting periods. The result indicates a significant differentiation of factors, that affect the timber carting out depending on the timber harvesting periods. The object of research is the logging areas of the Krasnoyarsk krai, which is one of the largest regions of Siberia.
\end{abstract}

\section{Introduction}

The logging industry is one of the most important in the country's forest industry. Wood resources that come from logging are processed into many valuable products. At the same time, the formation of product prices, the quality of the goods received and the volume of secondary wood resources depend on the volume and quality of the incoming raw materials [3].

Logging enterprises in the course of their activities often carry out three main interrelated technological processes: directly timber harvesting, transshipment and storage operations and transportation (carting out) of wood. Many factors have a significant impact on each of them [5]. At the same time, in addition to production and organizational and economic factors, the timber carting out is significantly affected by natural and climatic conditions [10-14]. Indeed, the timber carting out from the forest is carried out along long routes (in Siberia, up to 200$300 \mathrm{~km}$ ) with various terrain, soils, and road surfaces. Climate conditions are one of the most important factors influencing the timber carting out. At the same time, conditions can change daily in the sharply continental conditions of Siberia, and often within one day. Obviously, the speed of logging trucks varies significantly on a clear cold day in winter and a rainy day in autumn [8]. Thus, natural and climatic conditions have a significant impact on the speed of movement of timber carriers and on the volume of carting out. The purpose of this research is assessment these dependencies and compilation of appropriate regression models.

* Corresponding author: medvedev_serega@yandex.ru 


\section{Methods and Materials}

The object of research is automobile logging roads located on the territory of different logging regions of the Krasnoyarsk krai (Boguchansky, Yeniseisky, Motyginsky). Territories differ in natural and climatic conditions. The research used data on timber harvesting and carting out from the forest territory to the coastal lower warehouses for the period 2017-2019. As natural and climatic factors, the data that are stored in the weather archives on the rp5.ru electronic resource were analyzed. Data were taken for similar periods of time and for the corresponding meteorological posts (Boguchansky, Nazimovsky, Yeniseysky, Motyginsky).

The entire timber harvesting process (including taking into account the timber carting out from the forest territory) is divided into five periods due to the heterogeneity of natural, climatic and production conditions in different time intervals, as well as the possibility of their classification by the closest characteristics. [15]:

- winter (November 11-March 20);

- winter-spring (March 21-April 20);

- spring (April 21-June 30);

- summer (July 1 - August 31);

- autumn (September 1-November 10).

This periodization is typical for logging regions of Siberia, which are characterized by a significant length of winter (natural and climatic conditions with negative temperatures) and a shift in spring conditions. [6]. In accordance with this, there is an additional winterspring period, with transitional characteristics.

Statistical data was processed using the «Statistica 10.0» statistical product. Modeling was carried out using standard methods that have been successfully applied in practice [1, 9].

Previously, the authors obtained results on the significant dependence of timber carting out from the forest territory on natural and climatic factors in each of these areas $[2,10$, 11]. This has led to the need to conduct research and develop models that reflect dependencies for the entire region.

\section{Results and Discussion}

One of the theses regularly stated by the community of timber producers and loggers is the dependence of the volume of carting out on the air temperature. The main focus is on the winter time period $[4,13]$.

The research found that there is no obvious dependence between the air temperature and the volume of carting out. The deviation of data for carting out to the lower warehouse is too large to form both a model and separate dependencies. At the same time, the figure 1 shows that there is a General trend to reduce the volume of carting out goods when the temperature falls.

The concentration of working parameters of timber carting out to the lower warehouse is observed at temperatures in the range from -8 до $-31{ }^{\circ} \mathrm{C}$ (figure 2). At the same time, the most common volumes of daily carting out are $100-800 \mathrm{~m}^{3} /$ day. it should be noted that the illustrations shown in the figure characterize the carting out of the studied forest areas using an identical number of logging equipment. The working conditions of the equipment are also determined by the road capacity, which is similar in the studied areas. 
During the assessment of the influence of a complex of natural and climatic factors on the timber carting out to the lower warehouse, it was found that there are no regression models with a high coefficient of determination $(\mathrm{R}>0,8)$. This fact is due to the presence of many production variables that determine production and affect the amount of cargo transported in certain time intervals. These factors may include the condition of equipment, availability of free space (warehouses), the ability to pay for labor costs of personnel and leased equipment, etc. However, acceptable models (at $0.5<\mathrm{R}^{2}<0.7$ ) of the dependence of the volume of timber carting out to the lower warehouse on the complex of natural and climatic factors can be obtained. Thus, the dependence on factors 2 and 7 is most pronounced for the winter period (figure 3). It is clearly visible that the more the range of visibility and the lower the wind speed, the higher the volume of carting out in winter period. It is obvious that drivers of logging trucks are forced to slow down in difficult weather conditions (poor visibility and strong wind), and the volume of timber carting out with a constant number of logging trucks is steadily and objectively decreasing.

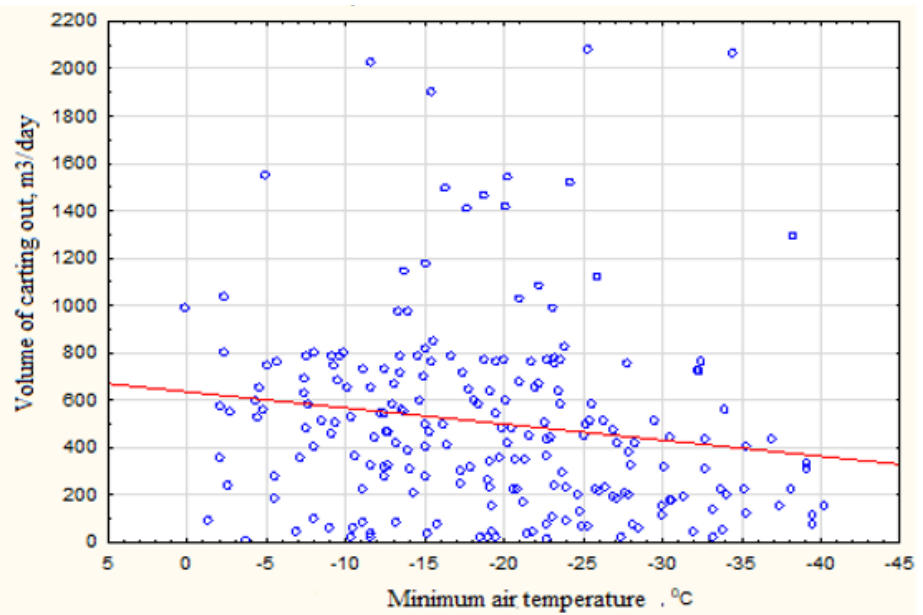

Fig. 1. Dependence of the volume of carting out to the lower warehouse on the minimum daily air temperature.

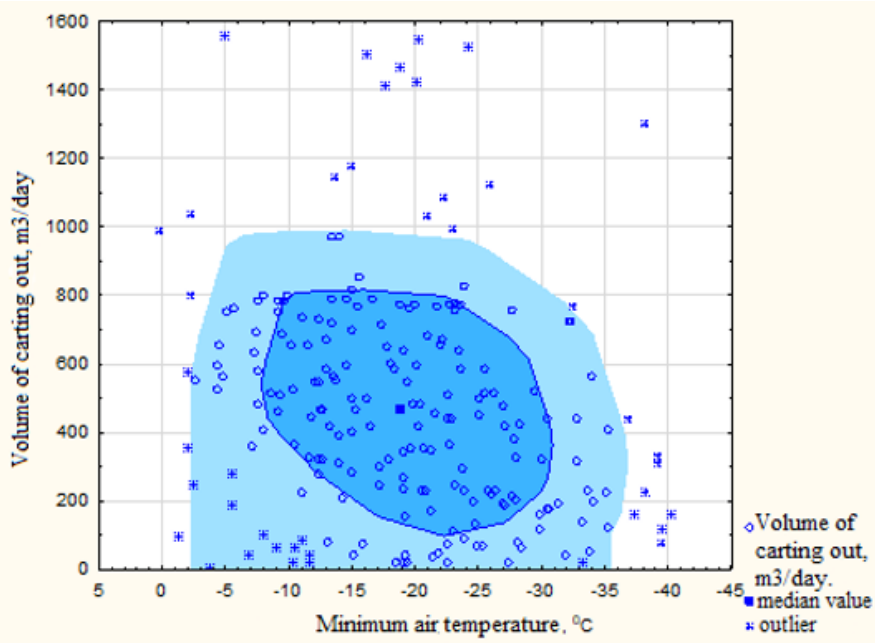

Fig. 2. Graph of the concentration of the volume of timber carting out to the lower warehouse depending on the minimum daily air temperature. 
According to the analysis, two more significant factors that affect the timber carting out to the lower warehouse are relative humidity and minimum air temperature (figure 4). The dependence of carting out on temperature shown in figure 1 is supplemented in this case by the influence of air humidity. It is obvious that the operation of the equipment is significantly complicated when the air humidity is too high (and the temperature is too low) - there is icing (both equipment and roadbed), which leads to a decrease in the productivity of carting out.

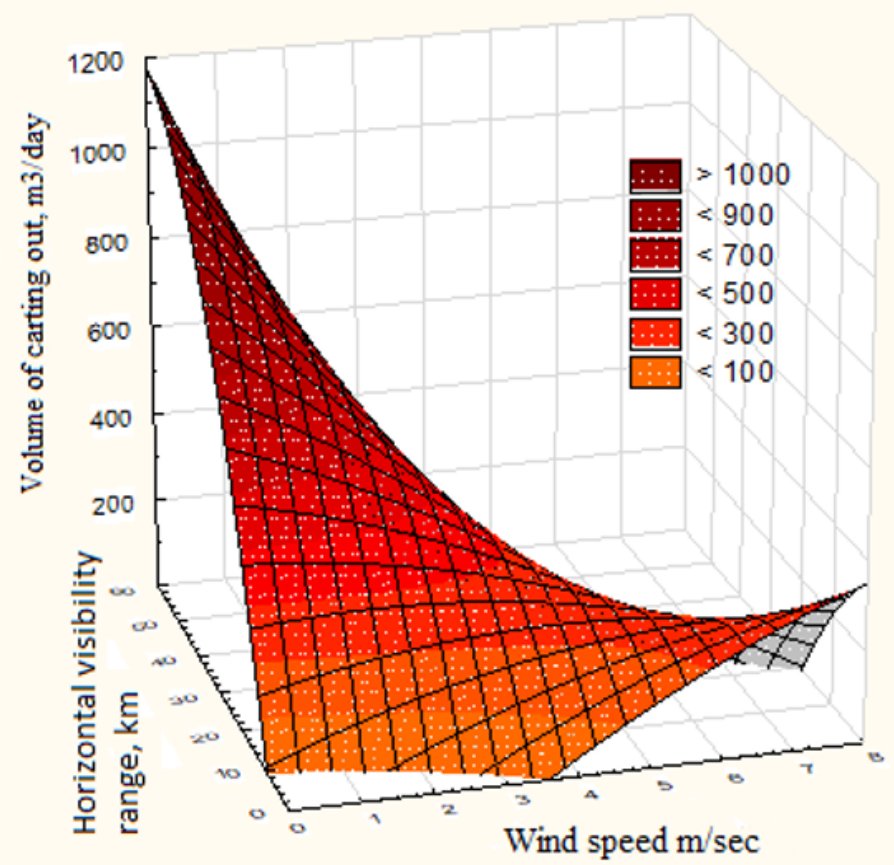

Fig. 3. Dependence of the volume of timber carting out to the lower warehouse depending on the horizontal visibility range and wind speed in winter.

In the course of the study, only regression dependencies were obtained for each of the studied carting out periods, due to the inability to represent graphically the carting out dependencies on several parameters. A model of the type was used as the basis:

$$
Y=b_{0}+\sum_{i=1}^{n} b_{i} v_{i}+\sum_{i=1}^{n} b_{i i} v_{i}^{2}+\sum_{\substack{i, j=1 \\ i \neq j}}^{n} b_{i j} v_{i} v_{j}
$$

Where $Y$ - dependent variable; (the volume of wood transported by one car for the dhauling distance per day, $\mathrm{m}^{3 *} \mathrm{~km} / \mathrm{car} *$ day);

$b_{i}$ - coefficient for the $\mathrm{i}$-th independent variable;

$b_{i i}$ - coefficient for the i-th independent variable squared;

$b_{i j}$ - coefficient for all possible pairwise products of independent variables (for $\mathrm{i} \neq \mathrm{j}$ ).

$n$ - number of independent variables;

$v_{i}$ - i-th independent variable 


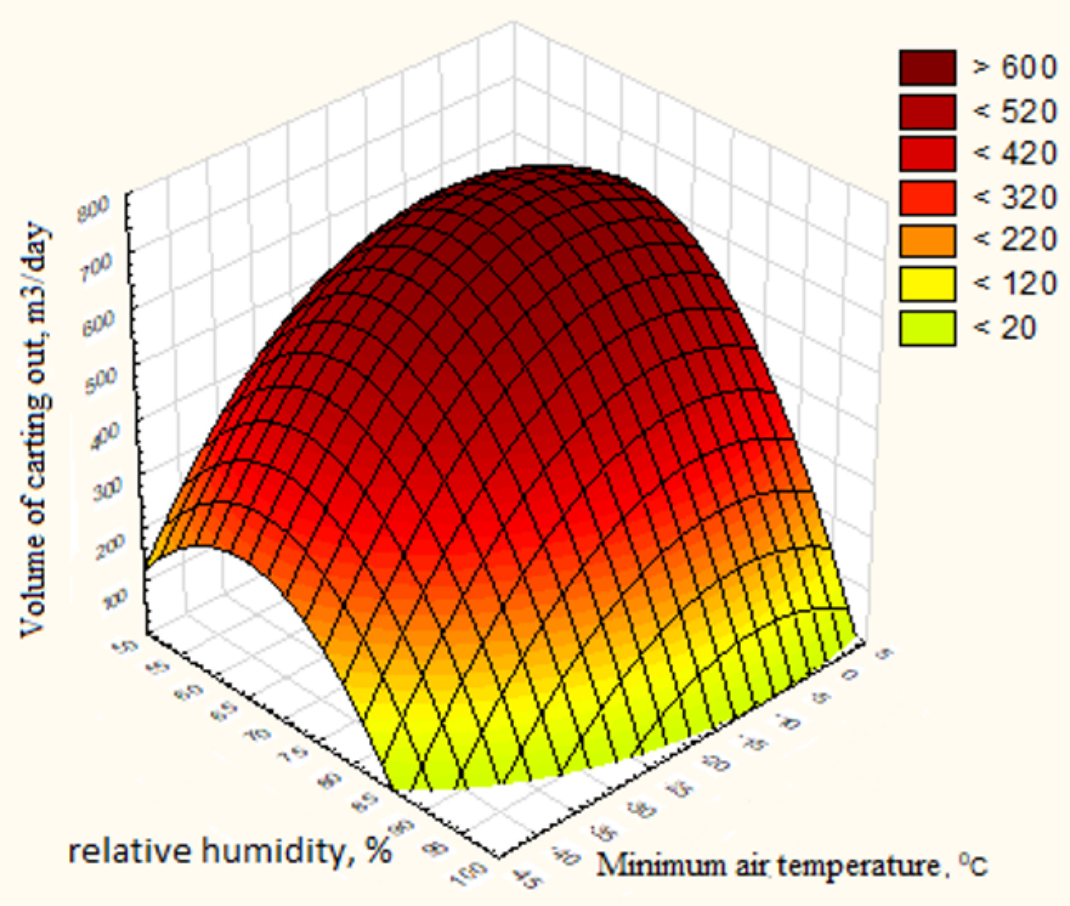

Fig. 4. Dependence of the volume of timber carting out to the lower warehouse depending on the relative humidity and minimum air temperature in winter.

In the case of four independent variables (identified during the study), the General model has the form:

$$
\begin{aligned}
Y=b_{0}+b_{1} v_{1}+b_{2} v_{2}+b_{3} v_{3}+b_{4} v_{4}+b_{11} v_{1}^{2}+b_{22} v_{2}^{2}+b_{33} v_{3}^{2}+b_{44} v_{4}^{2} \\
+b_{12} v_{1} v_{2}+b_{13} v_{1} v_{3}+b_{14} v_{1} v_{4}+b_{23} v_{2} v_{3}+b_{24} v_{2} v_{4}+b_{34} v_{3} v_{4}
\end{aligned}
$$

The research considered the influence of the following natural and climatic factors on the volume of specific timber carting out by a unit of equipment along the route to the lower warehouse in the conditions of the Krasnoyarsk region:

1. W - Relative humidity, $\%$.

2. S - Wind speed, $\mathrm{m} / \mathrm{sec}$.

3. O-type of precipitation. The research found that the following precipitation type characteristics are used to obtain numerical values of this factor:

- continuous rain-1.5;

- continuous snow-1.5;

- haze-0.5;

- snow shower-2;

- heavy rain-2;

- fog-1;

4. P - Duration of precipitation. To accept the numerical values, the duration of precipitation is taken:

- heavy rain-2;

- rain -1 ;

- snow or sleet -1.5 ; 
- fog-0.5.

5. Tmin - minimum air temperature per day, ${ }^{0} \mathrm{C}$.

6. Tmax - maximum air temperature per day, ${ }^{0} \mathrm{C}$.

7. V - The horizontal range of visibility, $\mathrm{km}$

8. $\mathrm{R}$ - the amount of precipitation, $\mathrm{mm}$.

9. $\mathrm{S}$ - height of snow cover, cm (if available).

An example of a table with source data is shown in table 1.

Table 1. Sample source data for the study

\begin{tabular}{|l|c|c|c|c|c|c|c|c|c|c|}
\hline Date & $\mathrm{W}$ & $\mathrm{S}$ & $\mathrm{O}$ & $\mathrm{P}$ & $\mathrm{Tmin}$ & $\mathrm{Tmax}$ & $\mathrm{V}$ & $\mathrm{R}$ & $\mathrm{S}$ & $\mathrm{Y}$ \\
\hline October 19, 2017 & 74 & 2 & 2.0 & 2 & -9.2 & 3.6 & 10 & 0.4 & 0 & 2349 \\
\hline October 18, 2017 & 85 & 1 & 1.5 & 1 & -2.2 & -0.5 & 10 & 3.0 & 0 & 5238 \\
\hline October 17, 2017 & 85 & 2 & 1.5 & 2 & -2.1 & 2.5 & 10 & 2.0 & 0 & 6615 \\
\hline
\end{tabular}

In the course of the study, the following models of dependencies for timber harvesting periods were obtained:

Autumn:

$\mathrm{Y}=2006.06+100.66 * \mathrm{~S}+1829.70 * \mathrm{~S}^{2}-625.09 * \mathrm{O}+4119.51 * \mathrm{O}^{2}-5629.76 * \mathrm{~S} * \mathrm{O}+$ 1049.78* Tmax $+16.63 * \mathrm{Tmax}^{2}-276.38 * \mathrm{~S} * \mathrm{~T} \max -444.75 * \mathrm{O} * \mathrm{~T} \max +3250.13 * \mathrm{P}+$ 1248.67* $\mathrm{P}^{2}-5768.98 * \mathrm{P} * \mathrm{~S}+2616.28 * \mathrm{O} * \mathrm{P}-78.06 * \mathrm{Tmax} * \mathrm{P}$

Summer:

$\mathrm{Y}=98705.3-1868.5 * \mathrm{Tmax}-814.4 * \mathrm{~V}-5.8 * \operatorname{Tmax}^{2}-13.2 * \mathrm{~V}^{2}-31.1 * \mathrm{Tm}^{2} * \mathrm{~V}-$ 40565.4*S $+3909.6 * \mathrm{~S}^{2}+215.8 * \mathrm{~S} * \mathrm{~T} \max +151.5 * \mathrm{~S} * \mathrm{~V}-74.3 * \mathrm{~W}-4.7 * \mathrm{~W}^{2}+124.7 * \mathrm{~W} * \mathrm{~S}$ $+6.1 * \mathrm{~W} * \mathrm{Tmax}+9.5 * \mathrm{~W} * \mathrm{~V}$

Spring:

$\mathrm{Y}=-7315.4-11845.1 * \mathrm{~S}+1364.3 * \mathrm{~V}+1658.9 * \mathrm{~S}^{2}-9.7 * \mathrm{~V}{ }^{2}+12.9 * \mathrm{~S} * \mathrm{~V}+$ $1242.7 * \mathrm{Tmax}-0.6 * \mathrm{Tmax}^{2}-116.6 * \mathrm{~S} * \mathrm{Tmax}-25.9 * \mathrm{~V} * \mathrm{~T} \max +18596.0 * \mathrm{P}-11622.9 * \mathrm{P}{ }^{2}$ $+1470.5 * \mathrm{~S} * \mathrm{P}-33.1 * \mathrm{~V} * \mathrm{P}+20.0 * \mathrm{Tmax} * \mathrm{P}$

Winter-spring:

$\mathrm{Y}=21864.51+407.04 * \mathrm{Tmin}+95.15 * \mathrm{~V}-14.51 * \mathrm{Tmin}^{2}+2.38 * \mathrm{~V}^{2}+8.39 * \mathrm{Tmin} * \mathrm{~V}+$ $514.38 * \mathrm{~S}+698.82 * \mathrm{~S}^{2}-80.82 * \mathrm{~S} * \mathrm{Tmin}-76.08 * \mathrm{~S} * \mathrm{~V}-521.17 * \mathrm{~W}+4.56 * \mathrm{~W}^{2}-$ $68.75 * \mathrm{~W} * \mathrm{~S}-8.18 * \mathrm{~W} * \mathrm{Tmin}+2.27 * \mathrm{~W} * \mathrm{~V}$

Winter:

$\mathrm{Y}=4304.29-435.75 * \mathrm{Tmin}+503.55 * \mathrm{~V}-0.25 * \mathrm{Tmin}^{2}-3.50 * \mathrm{~V}^{2}-1.42 * \mathrm{Tmin} * \mathrm{~V}-$ $5551.48 * \mathrm{~S}+59.71 * \mathrm{~S}^{2}-30.80 * \mathrm{~S} * \mathrm{Tmin}-124.39 * \mathrm{~S} * \mathrm{~V}+78.49 * \mathrm{~W}-2.40 * \mathrm{~W}^{2}+$ $93.79 * \mathrm{~W} * \mathrm{~S}+5.29 * \mathrm{~W} * \mathrm{Tmin}+1.37 * \mathrm{~W} * \mathrm{~V}$

The obtained regression models reflect the impact on the cubic kilometer of timber carried out to the lower warehouse by a unit of equipment per day in the logging areas of the Krasnoyarsk region.

As part of the assessment of the influence of various climatic conditions on timber carting out, it is impossible to ignore other factors besides those considered in this study production, infrastructure, natural (terrain, soil, etc.). According to the authors, there are two ways to solve the problem within the framework of constructed models and regression dependencies:

1. Inclusion of additional parameters in the list of analyzed factors and carrying out regression analysis taking into account their influence [7].

2. Inclusion of additional parameters as coefficients (correction) in models obtained earlier in various versions.

Obviously, the first way is preferable, because It excludes the least significant factors at the preliminary assessment stage (for example, calculating the Spearman correlation). 
However, including additional parameters in the resulting models is a difficult discussion task. In particular, this is due to the complexity of bringing a number of production indicators of logging enterprises to numerical values.

\section{Conclusion}

In the course of the research, regression dependences of the influence of natural and climatic factors on timber carting out from the forest territory were established. The object of research is the logging areas of the Krasnoyarsk region. It is possible to use the obtained models and approach to assessment in other logging regions of the country. The main purpose of such research is to identify patterns of changes in the volume of transported timber under the influence of natural and climatic factors. This data is important both from a theoretical point of view and from a practical point of view - for planning the activities of different enterprises involved in the logging process.

The reported study was funded by a grant from the President of the Russian Federation - for young scientists, candidates of sciences MK-1902.2019.6 and by Russian Foundation for Basic Research, Government of Krasnoyarsk Territory, Krasnoyarsk Regional Fund of Science, to the research project: «Research and modeling of economic development of the forest industry in the region in the context of climatic conditions and resource potential», grant № 18-410-240003.

\section{References}

1. P.M. Mazurkin, International Multidisciplinary Scientific GeoConference Surveying Geology and Mining Ecology Management, 427-340 (2014)

2. S. Medvedev, T. Rjabova, A. Mokhirev, IOP Conference Series: Earth and Environmental Science, 012036 (2019)

3. V.V. Zozulya, V.V. Sakhanov, S.O. Medvedev, Yu.A Bezrukih, O.V. Romanchenko, 17th International multidisciplinary scientific geoconference, 909-16 (2017)

4. V.V. Borovik, A.P. Kruglov, Science and technology in the road industry, 21-3 (2015)

5 D.V. Demakov, Perspectives of science, 9, 98-100 (2012)

6. M.V. Kabanov, V.N. Lykosov, Optics of the atmosphere and ocean, 9, 753-64 (2006)

7. A.V. Konstantinov, T.S. Koroleva, E.A. Kushnir, I.O. Torzhkov, Forest engineering magazine, 4, 257-74 (2017)

8. P.M. Mazurkin, Rational nature management: forest and logging (Yoshkar-Ola, 2006)

9. E.V. Morozov, I.R. Shegelman, Global scientific, 9, 67-71 (2011)

10. A.P. Mokhirev, E.V. Goryaeva, M.P. Mokhirev, A.V. Ivshina, Forest Engineering journal, 9, 176-85 (2018)

11. A.P. Mokhirev, S.O. Medvedev, O.N. Smolina, Forest Engineering journal, 3, 10-13 (2019)

12. E.A. Prokopev, N.A.Roslyakova, P.A. Ryazantsev, Drucker's Bulletin, 5, 173-85 (2017)

13. I.R.bShegelman, L.V. Shchegoleva, V.M. Lukashevich, Forest magazine, 2, 54-7 (2007)

14. K.V. Khoroshilov, V.K. Katarov, T.A. Gavrilov, G.N. Kolesnikov, Resources and Technology, 2, 59-75 (2019) 